\title{
Effects and mechanism of siomycin $A$ on the growth and apoptosis of MiaPaCa-2 cancer cells
}

\author{
BIN WANG ${ }^{1}$, WEI WANG ${ }^{1}$, HAO-YI MENG ${ }^{1}$, JING CHEN $^{2}$ and LI-JIE YUAN ${ }^{1}$ \\ ${ }^{1}$ Hebei Key Laboratory for Chronic Diseases, Tangshan Key Laboratory for Preclinical and \\ Basic Research on Chronic Diseases, School of Basic Medical Sciences; ${ }^{2}$ College of Life Science, \\ North China University of Science and Technology, Tangshan, Hebei 063210, P.R. China
}

Received August 29, 2018; Accepted June 6, 2019

DOI: $10.3892 / 01.2019 .10633$

\begin{abstract}
Siomycin A is a type of thiopeptide antibiotic that is isolated from the fermentation products of an endophytic actinomycin, which is derived from the medicinal plant Acanthopanax senticosus. The present study investigated whether siomycin A has antitumor effects in vitro on a variety of cell lines. A Cell Counting Kit-8 assay was performed to detect the effects of siomycin A on cell viability; morphological changes in the MiaPaCa-2 cell line were analyzed using an inverted phase contrast microscope. A Transwell migration assay was applied to detect cell migration ability. The cytoskeleton was observed by laser confocal microscopy, and apoptosis was detected using flow cytometry. A western blot assay was used to detect the expression of matrix metalloproteinase (MMP)-2, MMP-9 and $\alpha$-tubulin. The results revealed that siomycin A inhibited the proliferation of human tumor cell lines of different origins. As the concentration of siomycin A increased, the cell density decreased gradually and cells exhibited a morphological change from spindle to spherical shape. Furthermore, $24 \mathrm{~h}$ after administration, the cell migration ability was inhibited. The cytoskeleton complexity and morphological changes were increased after administration of siomycin A. The percentage of apoptotic cells was significantly increased and the expression levels of MMP-2, MMP-9 and $\alpha$-tubulin were downregulated by siomycin $\mathrm{A}$. Therefore,
\end{abstract}

Correspondence to: Professor Li-Jie Yuan, Hebei Key Laboratory for Chronic Diseases, Tangshan Key Laboratory for Preclinical and Basic Research on Chronic Diseases, School of Basic Medical Sciences, North China University of Science and Technology, 21 Bohai Road, Caofeidian Xincheng, Tangshan, Hebei 063210, P.R. China

E-mail: yuanlijie1970@163.com

Professor Jing Chen, College of Life Science, North China University of Science and Technology, 21 Bohai Road, Caofeidian Xincheng, Tangshan, Hebei 063210, P.R. China

E-mail: chjingchuchu@hotmail.com

Key words: siomycin A, proliferation, migration, apoptosis, cytoskeleton siomycin A was determined to effectively inhibit the proliferative ability of a variety of human tumor cell lines. Siomycin A was also determined to affect the cytoskeleton of tumor cells by downregulating the expression of $\alpha$-tubulin protein.

\section{Introduction}

Malignant tumors are a major disease, and pose serious threat to human life and health (1). There are currently $>100$ known types of malignancy that affect humans (2). In recent years, the overall incidence of malignant tumors has exhibited an upward trend (3). Malignant tumors are the main cause of death, and the mortality rate of patients with malignant tumors is slightly lower compared with that due to heart disease, particularly in the majority of developed countries (4). In China, malignant tumors are the second major cause of mortalities in cities and rural areas (5). Patients who live in developed countries, including Europe and the United States have a five-year standardized survival rate of 60-70\%; however, a survival rate of $30.9 \%$ has been reported for China, while that of rural areas is half of that in cities (6). Therefore, it is imperative to identify more effective novel anti-tumor drugs.

The fermentation products of Actinomycetes are an important natural source of anti-tumor drugs and have various chemical structures (7). The majority of them have innovative mechanisms and are easy to mass produce. Siomycin A is a type of thiopeptide antibiotic that is isolated from the fermentation products of an endophytic actinomycin, which is derived from the medicinal plant Acanthopanax senticosus (8). At present, the inhibitory effect of siomycin A on tumor cells has only been demonstrated in a limited number of cell lines and the mechanism of siomycin A in tumor cells is not yet clear $(9,10)$. In the present study, a number of human tumor cell lines were selected to investigate whether siomycin A has antitumor effects in vitro.

\section{Materials and methods}

Cell lines, media and chemical compounds. Siomycin A was isolated and identified by Liu et al (11). In the present study, siomycin $\mathrm{A}$ at a final concentration of $0,0.625,1.25,2.5,5$ or $10 \mu \mathrm{mol} / \mathrm{l}$; medium containing $0.5 \%$ dimethyl sulfoxide or $0 \mu \mathrm{mol} / 1$ siomycin A served as the controls. The K562 
human leukemia cell line, MCF7 human breast cancer cell line and $\mathrm{MiaPaCa}-2$ human pancreatic cancer cell line were purchased from the Cell Center, Peking Union Medical College (Beijing, China). Dulbecco's Modified Eagle's medium (DMEM) was obtained from Corning Inc., and fetal bovine serum (FBS) was purchased from Bovogen Biologicals Pty Ltd. Triton X-100, dimethyl sulfoxide and DAPI were acquired from Sigma-Aldrich (Merck KGaA). Transwell chambers were obtained from BD Pharmingen (BD Biosciences). $\alpha$-tubulin and $\beta$-actin antibodies were purchased from Antibody Revolution company, and matrix metalloproteinase (MMP)-2 and MMP-9 antibodies were acquired from Affinity Biosciences. Peroxidase-labeled antibody to mouse immunoglobulin $\mathrm{G}(\mathrm{IgG})$ was purchased from KPL Inc.

Cell culture. The K562 cell line was cultured with RPMI-1640 medium (Invitrogen; Thermo Fisher Scientific, Inc.). The MCF7 and MiaPaCa-2 cell lines were grown in DMEM medium (Corning Inc.). Both types of media were supplemented with $10 \%$ FBS and $1 \%$ penicillin-streptomycin (Gibco; Thermo Fisher Scientific, Inc.). The cell lines were maintained at $37^{\circ} \mathrm{C}$ in $5 \% \mathrm{CO}_{2}$.

Viability assay. The viability assay was performed according to the manufacturer's protocols of the CCK-8 kit (Beijing Zoman Biotechnology Co., Ltd.). Cell suspensions (100 $\mu \mathrm{l}$; $3 \times 10^{4}$ cells $/ \mathrm{ml}$ ) with $10 \%$ FBS medium were added to a 96-well plate and the plate was incubated for $6 \mathrm{~h}$ at $37^{\circ} \mathrm{C}$. Subsequently, $10 \mu \mathrm{l}$ CCK-8 reagent was added to each well and then the cells were incubated for $2 \mathrm{~h}$ at $37^{\circ} \mathrm{C}$. The optical density at a wavelength of $450 \mathrm{~nm}$ was measured using an ELx800 microplate reader (BioTek Instruments, Inc.). Similar assays were performed after incubation for 24, 48 and $72 \mathrm{~h}$ and the experiments were performed in triplicate. Cell viability was expressed as the half maximum inhibitory concentration $\left(\mathrm{IC}_{50}\right)$ value and data were analyzed with the software Microsoft Office Excel 2010 (Microsoft Corporation).

Morphological changes. Briefly, $3 \times 10^{5} \mathrm{MiaPaCa}-2$ cells were incubated at $37^{\circ} \mathrm{C}$ for $24 \mathrm{~h}$ with or without siomycin $\mathrm{A}$ at concentrations of $0.625,1.25,2.5,5$ and $10 \mu \mathrm{mol} / 1$ in $60-\mathrm{mm}$ diameter tissue culture dishes. Subsequently, the medium was discarded and the cells were washed once with PBS. The morphological changes of the apoptotic cells were observed using an inverted phase contrast microscope (CX31; Olympus Corporation, Tokyo, Japan) at x100 magnification.

Transwell migration assay. The assays were performed using a Corning Transwell permeable support system with $8.0 \mu \mathrm{m}$ pore size. A total of $1 \times 10^{4}$ cells were suspended in serum-free DMEM and were placed in the upper chamber of a Transwell plate. Siomycin A at a final concentration of $0,0.625,1.25,2.5$, 5 or $10 \mu \mathrm{mol} / 1$ was added to the lower chamber, which DMEM containing $10 \% \mathrm{FBS}$. After incubation for $20 \mathrm{~h}$ at $37^{\circ} \mathrm{C}$, the cells on the upper surface of the filter were removed using a cotton swab, 2 drops of the Rapid Gram Stain (Zhuhai Baso Biotechnology Co., Ltd.) solution were added to the cells that had migrated to the membrane at room temperature for $30 \mathrm{sec}$ and were washed with water. Migration was observed in six randomly selected fields with a light Olympus CX31 microscope. Cells in each image were counted with the ImageJ 1.52a software (National Institutes of Health, USA).

Cytoskeleton assay. MiaPaCa-2 cells were inoculated into laser confocal culture dishes at a density of $6 \times 10^{4}$ cells/well and cultured for $24 \mathrm{~h}$. The cells were treated and incubated with various concentrations of Siomycin A. After rinsing three times with Hank's Balanced Salt Solution (HBSS; Beijing Solarbio Science \& Technology Co., Ltd.), cells were incubated with $200 \mu \mathrm{l}$ murine anti-human $\alpha$-tubulin (1:200; cat. no. ARH4207; Antibody Revolution Inc.) overnight at $4^{\circ} \mathrm{C}$ in a wet box. Cells were then washed with HBSS three times for $10 \mathrm{~min}$ and incubated with $200 \mu \mathrm{l}$ goat anti-mouse IgG-fluorescein isothiocyanate (FITC) (1:50; cat. no. 074-1506; SeraCare Life Sciences) at room temperature for $30 \mathrm{~min}$ in the dark. Cells were washed three times with HBSS for $10 \mathrm{~min}$ and incubated with $10 \mu \mathrm{l}$ DAPI nuclear stain for $5 \mathrm{~min}$ at room temperature in the dark. The unbound nuclear stain was washed with HBSS. The dishes were placed under a laser scanning confocal microscope (TCS SP8 STED 3X; Leica Microsystems $\mathrm{GmbH}$; magnification, x600) and scanned at $488 \mathrm{~nm}$ (excitation) and $543 \mathrm{~nm}$ (detection) for the analysis of green fluorescence. A total of five fields were randomly scanned for each group to obtain fluorescence images and analyzed with ImageJ 1.6.0_24 software (National Institutes of Health), in order to observe the cytoskeleton of the cells.

Apoptosis detection by flow cytometry. Cells that have reached $\sim 80 \%$ confluence were detached using $0.25 \%$ trypsin without EDTA (Beijing Solarbio Science \& Technology Co., Ltd.) at $37^{\circ} \mathrm{C}$. The control and treated cells were stained using an Annexin V-FITC/propidium iodide (PI) apoptosis detection kit (BD Biosciences), according to the manufacturer's protocols. After double staining with FITC-conjugated Annexin V and PI, the cells were analyzed by flow cytometry (Leica TCS SP8 STED; Leica Microsystems GmbH). The experiments were performed in triplicate (SPSS 19.0; IBM Corp.).

Western blotanalysis. All of the treated cell groups were harvested and lysed with cell lysis buffer (cat. no. BB-3201-1; BestBio) for western blot analysis. The protein concentrations were determined by a NanoDrop 2000 spectrophotometer (NanoDrop Technologies; Thermo Fisher Scientific, Inc.). Proteins (5-10 $\mu \mathrm{l}$, 10-30 $\mu \mathrm{g}$ ) were separated using 8-10\% SDS-PAGE and transferred to polyvinylidene difluoride membranes (EMD Millipore). The membranes were blocked in TBST containing 5\% non-fat skim milk at room temperature for $2 \mathrm{~h}$. After washing with TBST in triplicate, the membranes were incubated with primary antibodies against MMP-2 (1:500; cat. no. AF0577; Affinity Biosciences), MMP-9 (1:1,500; cat. no. AF5228; Affinity Biosciences), $\alpha$-tubulin (1:5,000; cat. no. ARH4207; Antibody Revolution Co., Ltd.) and $\beta$-actin (1:5,000; cat. no. ARH4149; Antibody Revolution Co., Ltd.) for $2 \mathrm{~h}$ at $37^{\circ} \mathrm{C}$. Subsequently, the membranes were washed and incubated with an appropriate horseradish peroxidase-linked secondary antibody (1:5,000; cat. no. 074-1506; KPL Inc.) for $20 \mathrm{~min}$ at $37^{\circ} \mathrm{C}$. Bands were developed with an enhanced chemiluminescence blot detection system (UVP BioSpectrum Imaging System; Analytik Jena AG). The data were analyzed via densitometry using ImageJ 1.52a software (National Institutes of Health). 
Statistical analysis. Statistical comparisons were performed with SPSS 19.0 software (IBM Corp.). The results are presented as the mean \pm standard deviation. One-way analysis of variance was used for multiple comparisons followed by a Student-Newman-Keuls post hoc test. $\mathrm{P}<0.05$ was considered to indicate a statistically significant difference.

\section{Results}

Siomycin A inhibits the proliferation of human tumor cell lines. Siomycin A inhibited the proliferation of a variety of human tumor cell lines. Cell viability was reduced with increases in drug concentration, which demonstrates a dose-dependent effect. Furthermore, cell viability markedly decreased as the drug treatment period increased, which demonstrates a time-dependent association (Fig. 1). Among the three cell lines, the $\mathrm{IC}_{50}$ of the human leukemia $\mathrm{K} 562$ cells was the lowest at $6.25 \pm 3.60 \mu \mathrm{mol} / 1$ at $24 \mathrm{~h}$, while that for the human pancreatic cancer MiaPaCa-2 cells was $6.38 \pm 5.73 \mu \mathrm{mol} / 1$. However, the $\mathrm{IC}_{50}$ of the human pancreatic cancer MiaPaCa-2 cells at 48 and $72 \mathrm{~h}$ were the lowest of the three cell lines, which were $0.76 \pm 0.51$ and $0.54 \pm 0.02 \mu \mathrm{mol} / 1$, respectively (Table I). Therefore, MiaPaCa-2 cells were selected for the subsequent experiments.

Siomycin A changes the morphology and inhibits the migration of MiaPaCa-2 cells. The MiaPaCa- 2 cells were treated with different concentrations of siomycin A for $24 \mathrm{~h}$ and then changes in cell morphology were observed under an inverted phase contrast microscope. The cells in the solvent, and $0,0.625$ and $1.25 \mu \mathrm{mol} / 1$ groups had a high cell density and a better growth state. Furthermore, there was no significant difference in the cell morphology of these groups. When the concentration of siomycin A was $2.5 \mu \mathrm{mol} / 1$, the cell density began to decrease and the cell size was reduced, but the cells remained spindle-shaped. In the 5 and $10 \mu \mathrm{mol} / 1$ groups, a large number of cells had shrunk into a spherical shape and exhibited many small bright spots; the cell density was notably reduced (Fig. 2A). Subsequently, the effect of siomycin A on the migration of the MiaPaCa-2 cells was detected. After treatment with various concentrations of siomycin A for $24 \mathrm{~h}$, the number of cells penetrating into the Transwell chamber was reduced with increases in drug concentration (Fig. 2B). Compared with the $0 \mu \mathrm{mol} / 1$ group, cell mobility was significantly reduced in the $2.5,5$ and $10 \mu \mathrm{mol} / 1$ groups $(\mathrm{P}<0.05)$.

Effects of siomycin A on the cytoskeleton of MiaPaCa-2 cells. The MiaPaCa-2 cells were treated with various concentrations of siomycin A for $24 \mathrm{~h}$, and then the changes in the cytoskeletons were detected using a laser confocal microscope. In the $0 \mu \mathrm{mol} / 1$ group, the distribution of green filamentous microtubules in the cytoplasm of the MiaPaCa- 2 cells was regular and they were arranged radially from the nucleus to the surroundings. With the increase in drug concentration, the cell began to shrink, the number of microtubules reduced or had disappeared, the fluorescence distribution was clustered and partially contracted to the nucleus, and the fluorescence intensity was notably enhanced. There were slight changes in the nuclei of the cells in the 2.5, 5 and $10 \mu \mathrm{mol} / 1$ groups (Fig. 3). The images were processed according to the method
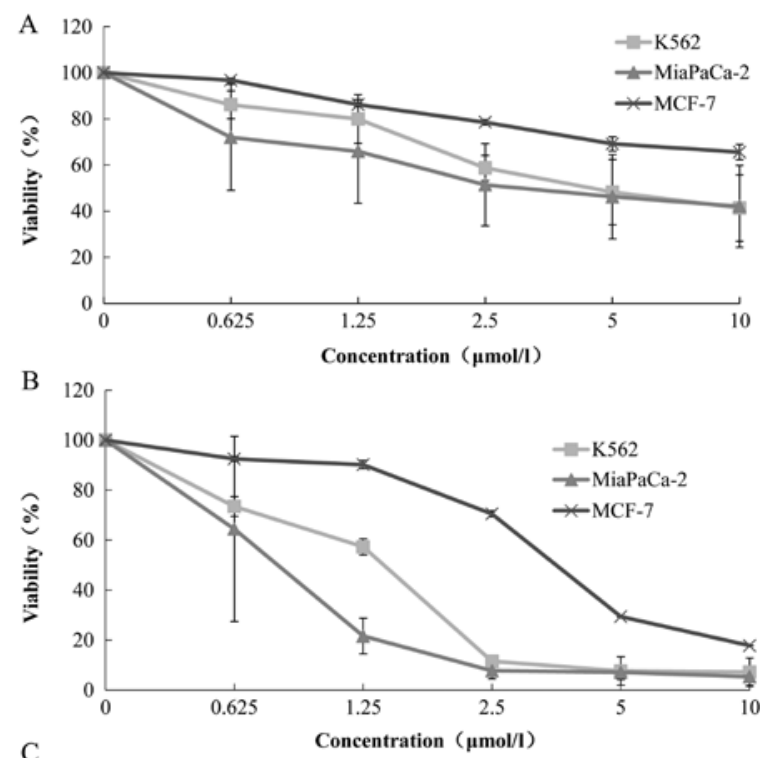

C

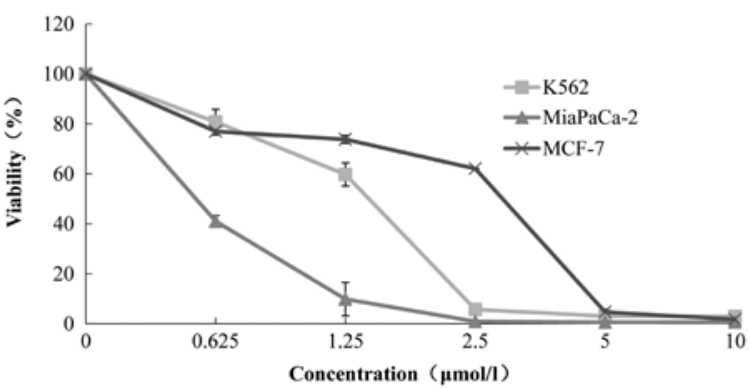

Figure 1. Siomycin A inhibits cell growth. The cells were treated with various concentrations of siomycin A for (A) 24, (B) 48 and (C) $72 \mathrm{~h}$, and cell viability was assessed using a CCK assay.

of a previous study (12). The distribution of the microtubule skeleton was analyzed with ImageJ software fractal box counting tool. The software automatically maps the abscissa $\log$ (box size) and ordinate $\log$ (count) values, and the resulting slope is the fractal dimension $\mathrm{D}$. The results are presented in Table II. The fractal dimensions of the 2.5, 5 and $10 \mu \mathrm{mol} / 1$ groups were significantly reduced compared with the $0 \mu \mathrm{mol} / 1$ group $(\mathrm{P}<0.05)$. The results demonstrated that the complexity of the cytoskeleton was reduced and the morphological differences in the cytoskeleton were increased in the MiaPaCa-2 cells that were treated with siomycin A.

Effects of siomycin A on the apoptosis of MiaPaCa-2 cells. Using Annexin V-FITC/PI double staining, analysis of the apoptosis of the MiaPaCa-2 cells treated with different concentrations of siomycin A demonstrated the potent proapoptotic effect of siomycin A. Compared with the $0 \mu \mathrm{mol} / 1$ group, the percentage of apoptotic cells was significantly increased in the $2.5,5$ and $10 \mu \mathrm{mol} / 1$ groups $(\mathrm{P}<0.05$; Fig. 4).

Effects of siomycin A on the protein levels of MMP-2, MMP-9 and $\alpha$-tubulin in MiaPaCa-2 cells. In order to investigate the mechanism of siomycin A on inhibiting migration and affecting the cytoskeleton of MiaPaCa-2 cells, the protein levels of MMP-2, MMP-9 and $\alpha$-tubulin were evaluated. The results of the western blot analysis demonstrated that the expression levels of MMP-2 and MMP-9 protein in the MiaPaCa-2 

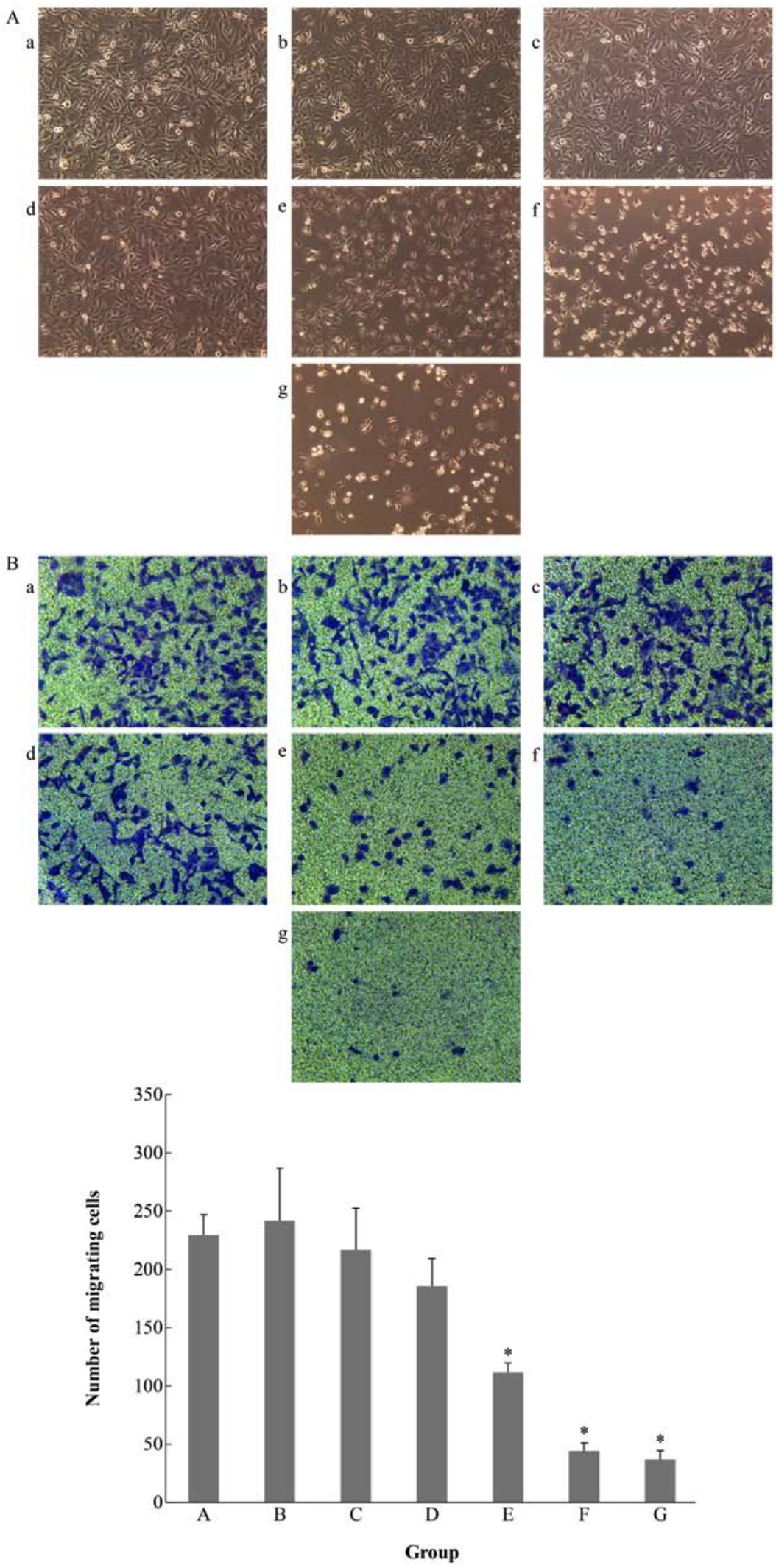

Figure 2. Effects of siomycin A on the morphology and migration of MiaPaCa-2 cells. The cells were treated with solvent control or $0,0.625,1.25,2.5,5$ and 1 $0 \mu \mathrm{mol} / 1$ siomycin A for $24 \mathrm{~h}$. (A) The changes in cell morphology were observed under an inverted phase contrast microscope (magnification, $\mathrm{x} 100)$. (B) The inhibition of $\mathrm{MiaPaCa}-2$ cell migration by siomycin $\mathrm{A} .{ }^{*} \mathrm{P}<0.05$ vs. the $0 \mu \mathrm{mol} / 1$ group. Aa-Ag and $\mathrm{Ba}-\mathrm{Bg}$ represent treatments with increasing concentrations of siomycin A (control and $0,0.625,1.25,2.5,5$ and $10 \mu \mathrm{mol} / 1)$.

cells were significantly reduced in the $2.5,5$ and $10 \mu \mathrm{mol} / 1$ groups. The expression of $\alpha$-tubulin protein was significantly decreased in the $1.25,2.5,5$ and $10 \mu \mathrm{mol} / 1$ groups compared with the $0 \mu \mathrm{mol} / \mathrm{l}$ group (Fig. 5). 
Table I. $\mathrm{IC}_{50}$ of three tumor cell lines at different time points.

\begin{tabular}{lrcc}
\hline & \multicolumn{3}{c}{$\mathrm{IC}_{50}(\mu \mathrm{mol} / \mathrm{l})$} \\
\cline { 2 - 4 } Cell line & \multicolumn{1}{c}{$24 \mathrm{~h}$} & $48 \mathrm{~h}$ & $72 \mathrm{~h}$ \\
\hline K562 & $6.25 \pm 3.60$ & $1.18 \pm 0.04$ & $1.24 \pm 0.12$ \\
MiaPaCa-2 & $6.38 \pm 5.73$ & $0.76 \pm 0.51$ & $0.54 \pm 0.02$ \\
MCF-7 & $19.61 \pm 7.28$ & $2.97 \pm 0.02$ & $1.98 \pm 0.03$ \\
\hline
\end{tabular}

$\mathrm{IC}_{50}$, half maximum inhibitory concentration.

Table II. Fractal dimension of MiaPaCa- 2 cells treated with different concentrations of siomycin A.

\begin{tabular}{lc}
\hline Concentration $(\mu \mathrm{mol} / \mathrm{l})$ & Cell dimension \\
\hline Control & $1.67 \pm 0.03$ \\
0 & $1.65 \pm 0.05$ \\
0.625 & $1.63 \pm 0.11$ \\
1.25 & $1.67 \pm 0.04$ \\
2.5 & $1.47 \pm 0.14^{\mathrm{a}}$ \\
5 & $1.37 \pm 0.17^{\mathrm{a}}$ \\
10 & $1.31 \pm 0.13^{\mathrm{a}}$ \\
\hline
\end{tabular}

${ }^{\mathrm{a}} \mathrm{P}<0.05$ vs. the $0 \mu \mathrm{mol} / 1$ group.

\section{Discussion}

The increasing incidence of malignant tumors necessitates the identification of novel therapeutic compounds. The majority of novel compounds identified originate from microbes (13). Siomycin A is a thiopeptide antibiotic that was isolated from the fermentation product of Streptomyces sioyaensis by Nishimura in 1959 (14). Using a high-throughput drug screening system, Radhakrishnan et al (9) demonstrated that siomycin A specifically inhibits the transcription and expression of Forkhead box family (Fox)M1 without affecting other members of the Forkhead box family. FoxM1 is a transcription factor of the Forkhead family (15) that is overexpressed in a variety of tumor cell types, including liver cancer, pancreatic cancer, breast cancer and lung adenocarcinoma cells (16-21).

A previous study demonstrated that siomycin A effectively reduces the expression of maternal embryonic leucine zipper kinase and inhibits tumor growth in mice (10). Another study found that siomycin A inhibits tumor cell growth and survival by downregulating the expression of BUB1 mitotic checkpoint serine/threonine kinase B protein (22). In addition, siomycin A can inhibit the invasive ability of laryngeal carcinoma HEp-2 cells and reduce the levels of MMP-2 and MMP-9 protein in them (23).

The present study demonstrated that siomycin A has an inhibitory effect on three human tumor cell lines in a time- and a dose-dependent manner. Based on the comprehensive evaluation of the $\mathrm{IC}_{50}$, the human pancreatic cancer MiaPaCa-2 cell

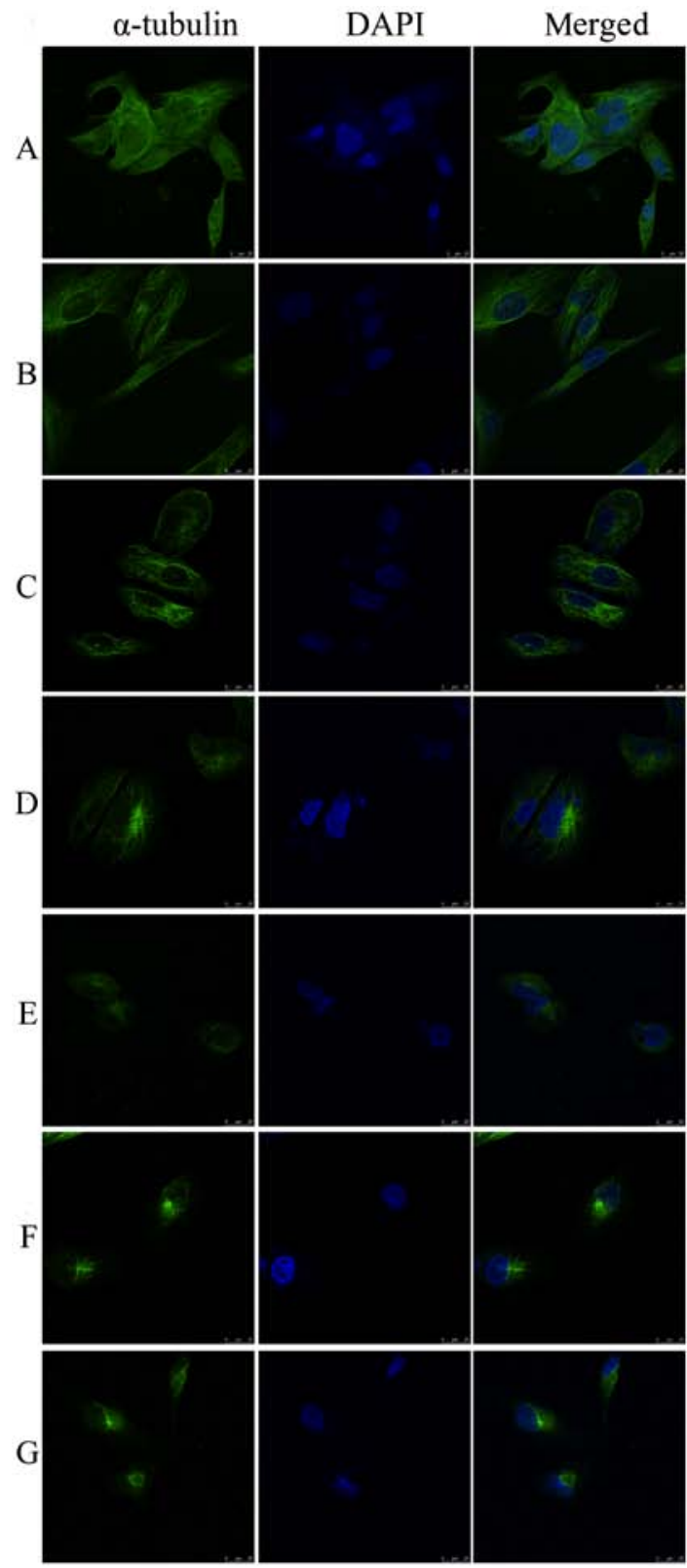

Figure 3. Effects of siomycin A on the cytoskeleton of MiaPaCa-2 cells. The cells were treated with solvent control, or $0,0.625,1.25,2.5,5$ and $10 \mu \mathrm{mol} / 1$ siomycin A for $24 \mathrm{~h}$. The cytoskeleton changes were observed under a laser confocal microscope. A-G represents treatments with increasing concentrations of siomycin A (control and 0,0.625, 1.25, 2.5, 5 and $10 \mu \mathrm{mol} / \mathrm{l}$ ).

line was selected as a model to analyze the inhibitory effect of siomycin A on tumor cells and investigate the underying mechanism.

The density of the human pancreatic cancer MiaPaCa-2 cells treated with siomycin A for $24 \mathrm{~h}$ was observed using an inverted phase contrast microscope. The cell density was reduced in response to siomycin A at concentration of $2.5 \mu \mathrm{mol} / 1$. With the increase in the drug concentration, shrunken cells that were rounded with small bright spots were observed. Under a light microscope, the common feature of apoptosis is cell shrinkage, and nuclear alterations (24). Apoptotic cells and bodies are clear under phase contrast microscopy (25). In the present study, the cells were notably shrunken and rounded, which is consistent with the 


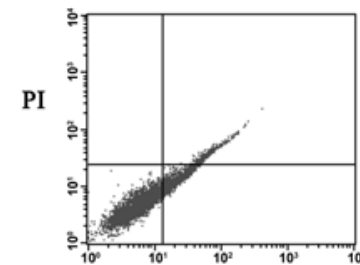

Annexin V

Control

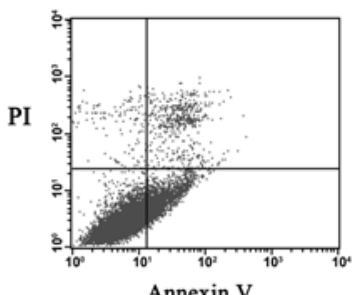

Siomycin A $1.25 \mu \mathrm{mol} / 1$

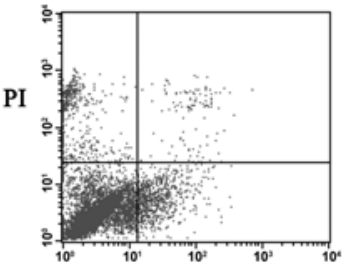

Annexin V

Siomycin A $0 \mu \mathrm{mol} / 1$

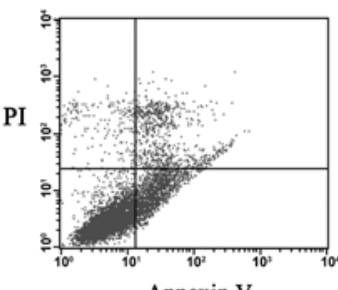

Annexin V

Siomycin A $2.5 \mu \mathrm{mol} / 1$

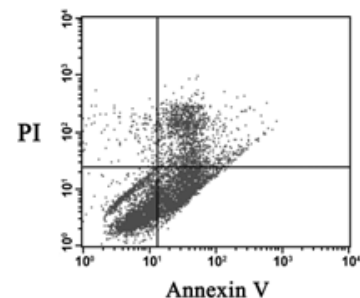

Siomycin A $10 \mu \mathrm{mol} / 1$

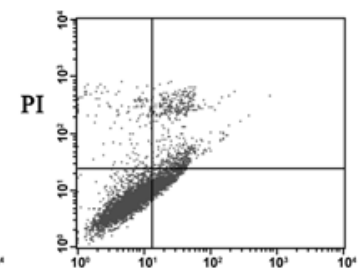

Annexin V
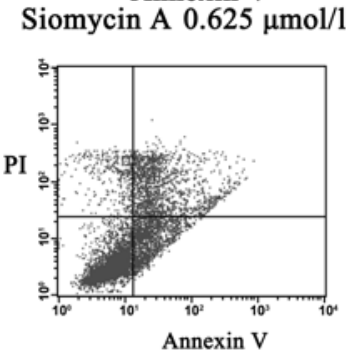

Siomycin A $5 \mu \mathrm{mol} / 1$

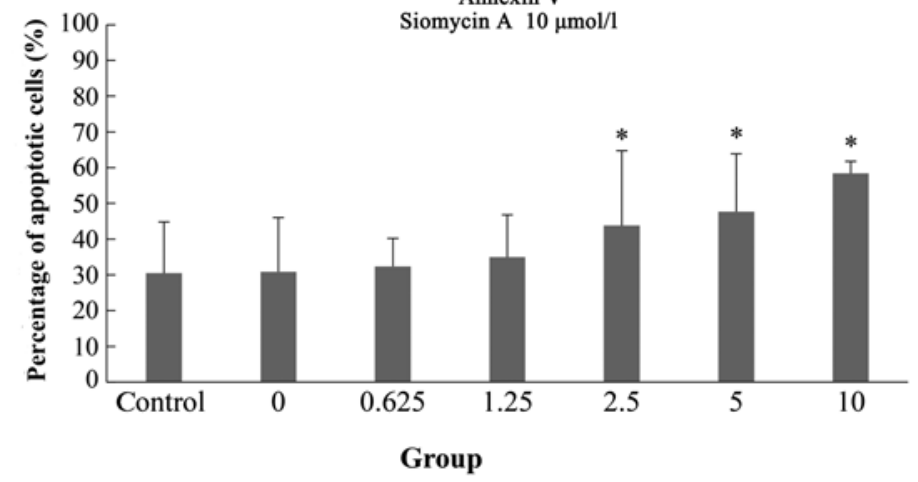

Figure 4. Effects of siomycin A on the apoptosis of MiaPaCa-2 cells. The apoptosis assay was performed with Annexin V-FITC/PI double staining and representative plots of the MiaPaCa-2 cells treated with the indicated dose of siomycin A are shown. The apoptotic ratio was calculated and plotted. ${ }^{*} \mathrm{P}<0.05$ vs. the $0 \mu \mathrm{mol} / 1$ group. FITC, fluorescein isothiocyanate; PI, propidium iodide.

A

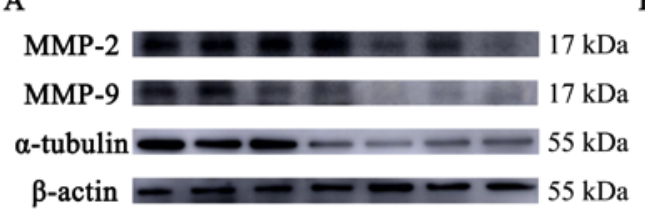

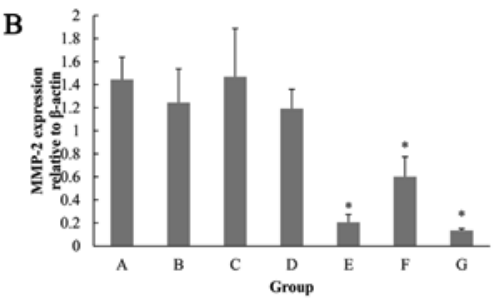

C

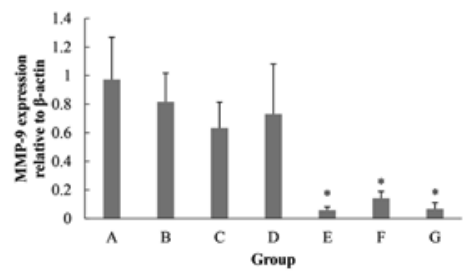

D

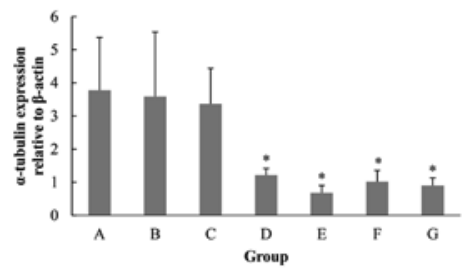

Figure 5. Effects of siomycin A on the protein levels of MMP-2, MMP-9 and $\alpha$-tubulin in MiaPaCa-2 cells. (A) Detection of MMP-2, MMP-9 and $\alpha$-tubulin protein expression by western blot. (B) Expression of MMP-2 relative to $\beta$-actin protein under different concentrations of siomycin A.(C) Expression of MMP-9 relative to $\beta$-actin protein under different concentrations of siomycin A. (D) Expression of $\alpha$-tubulin relative to $\beta$-actin protein under different concentrations of siomycin A. The cells were treated with solvent control, or $0,0.625,1.25,2.5,5$ and $10 \mu \mathrm{mol} / 1$ siomycin A for $24 \mathrm{~h}$. The protein levels were determined using western blot analysis. "P<0.05 vs. the $0 \mu \mathrm{mol} / 1$ group. MMP, matrix metalloproteinase. For each panel, A-G represents treatments with increasing concentrations of siomycin A (control and $0,0.625,1.25,2.5,5$ and $10 \mu \mathrm{mol} / \mathrm{l})$. 
morphological changes of apoptosis. The percentage of apoptotic MiaPaCa-2 cells was significantly increased with increases in drug concentration. When the drug concentration was $10 \mu \mathrm{mol} / 1$, the percentage of apoptotic cells reached $58.40 \pm 3.35 \%$ (Fig. 4), which demonstrates a dose-dependent effect. This result is consistent with the results of a previous study, which showed that siomycin A induces apoptosis of human laryngeal carcinoma HEp-2 cells (23).

In order to investigate the effect of siomycin A on the migration of tumor cells, a Transwell migration assay was used to detect changes in cell migration. Compared with the $0 \mu \mathrm{mol} / 1$ group, the number of migrated cells was significantly lower in the $2.5-10 \mu \mathrm{mol} / 1$ groups $(\mathrm{P}<0.05)$. The results suggest that siomycin $\mathrm{A}$ inhibited the migration of tumor cells; the aforementioned results are consistent with that of Jiang et al (26), who demonstrated that siomycin A inhibits the migration and invasion of human nasopharyngeal carcinoma C666-1 cells. Furthermore, the expression levels of MMP-2 and MMP-9 were detected using western blot analysis. The results demonstrated that the expression levels of MMP-2 and MMP-9 in the 2.5-10 $\mu \mathrm{mol} / 1$ groups were significantly lower than in the $0 \mu \mathrm{mol} / 1$ group $(\mathrm{P}<0.05)$. Therefore, the mechanism of the inhibitory effect of siomycin A on human pancreatic cancer cell migration may be associated with downregulation of MMP-2 and MMP-9 protein expression. The results are similar to those of Nakano et al (10), who treated polymorphic glioblasts with siomycin A, and demonstrated that the expression levels of MMP-2 and MMP-9 were reduced. Previous studies have shown the association of FoxM1 with MMP-2 and MMP-9 in various types of cancer, including clear cell renal cell carcinoma, glioma cells and papillary thyroid carcinoma, leading to the increased invasiveness and migratory ability of cancer cells causing metastasis, And targeting FoxM1 has been shown to inhibit these cellular properties via MMP-2 and MMP-9 downregulation (27-29).

In the initial morphological observation in the present study, tumor cells appeared to be shrunk and rounded after administration with siomycin $\mathrm{A}$, which suggests that the skeletal structure of the tumor cells may change. The cytoskeleton serves a role in diverse cellular functions, including maintenance of cell shape, cell movement, cell division and intracellular organization and trafficking (30). One of the main structures of the cytoskeleton is the microtubules, which serve an important role in maintaining cell morphology, organelle composition, cell division, intracellular transport of substances and signal transduction (31). Therefore, the expression of $\alpha$-tubulin was analyzed in the present study using laser confocal microscopy and western blot analysis. The results demonstrated that the microtubules in the cytoplasm reduced gradually or disappeared with increasing concentration of siomycin A. The microtubule contraction and the fluorescence around the nucleus were markedly enhanced, which indicated that the tubulin was depolymerized and rearranged. The measure of complex irregularity is reflected by the fractal dimension, which represents the validity of complex space. The analysis of the cell fractal dimension with ImageJ software identified that it was significantly different in the $2.5-10 \mu \mathrm{mol} / 1$ groups compared to the $0 \mu \mathrm{mol} / 1$ group $(\mathrm{P}<0.05)$. The results indicated that the cytoskeleton complexity was reduced by treatment with siomycin A, which is consistent with the morphological changes in the cells. The expression of $\alpha$-tubulin protein was detected by western blot analysis and the results demonstrated that the expression levels of $\alpha$-tubulin protein in the $1.25-10 \mu \mathrm{mol} / 1$ groups were significantly lower than those in the $0 \mu \mathrm{mol} / 1$ group $(\mathrm{P}<0.05)$. These results are consistent with that of the laser confocal microscopy, which were consistent with the trend of the cytoskeletal fractal dimension. It was observed that $\alpha$-tubulin protein expression decreased with the increase of siomycin $\mathrm{A}$ and the mechanism of siomycin A on the cytoskeleton of human tumor cells may be associated with the downregulation of $\alpha$-tubulin protein expression. However, regardless of this finding, it is still unclear whether the function of $\alpha$-tubulin in tumor cells depends on siomycin A, or not. Therefore, further examination on this subject is required.

In conclusion, the present study proposed that siomycin A inhibits the proliferation and migration of cancer cells, and demonstrated that siomycin A also induces cell apoptosis. The inhibitory effects of siomycin A on tumor cells may be associated with downregulation of $\alpha$-tubulin skeletal protein expression, which affects the cytoskeleton of tumor cells. Experiments of the present study were limited to investigations at the cellular level and these results are not sufficient to elucidate the anti-tumor mechanism of siomycin A. Further animal experiments will be conducted to elucidate the mechanism of siomycin A action, as well as the role of $\alpha$-tubulin skeletal protein.

\section{Acknowledgements}

Not applicable.

\section{Funding}

This study was supported by the National Science Foundation of Hebei Province (grant nos. C2014209137 and H2013209040).

\section{Availability of data and materials}

The datasets used and/or analyzed during the present study are available from the corresponding author on reasonable request.

\section{Authors' contributions}

BW, JC and LY designed experiments. BW, WW and HM performed experiments. BW analyzed the data. BW, JC and LY wrote the manuscript.

\section{Ethics approval and consent to participate}

Not applicable.

\section{Patient consent for publication}

Not applicable.

\section{Competing interests}

The authors declare that they have no competing interests. 


\section{References}

1. Ji-Jun D, Ya-Qiong Y, Nian-Nian Y, Jing Z, Rong-Shou Z and Si-Wei Z: International comparison analysis of china's cancer incidence and mortality. Chin J Frontiers of Med Sci (Electronic Version), 2016 (In Chinese).

2. Hu XQ, Zhou GQ and Wang SX: Application of combined detection of T lymphocyte and DNT cells in early diagnosis of malignant tumor. Labeled Immunoassays Clin Med 23: 139-142, 2016 (In Chinese)

3. Torre LA, Siegel RL, Ward EM and Jemal A: Global cancer incidence and mortality rates and trends-an update. Cancer Epidemiol Biomarkers Prev 25: 16-27, 2016.

4. Zaorsky NG, Churilla TM, Egleston BL, Fisher SG, Ridge JA, Horwitz EM and Meyer JE: Causes of death among cancer patients. Ann Oncol 28: 400-407, 2017.

5. Shengshou HU, Runlin GAO, Lisheng LIU, Manlu ZHU, Wen WANG, Yongjun WANG, Zhaosu WU, Huijun LI Dongfeng GU, Yuejin YANG, et al: Summary of the 2018 report on cardiovascular diseases in China. Chin Circulation J 34: 209, 2019 (In Chinese).

6. Chen W, Zheng R, Zhang S, Zhao P, Zeng H and Zou X: Report of cancer incidence and mortality in China, 2010. Ann Trans Med 2: 61, 2014

7. Sharma M, Dangi P and Choudhary M: Actinomycetes: Source, identification, and their applications. Int J Curr Microbiol App Sci 3: 801-832, 2014.

8. Li L, Ai-Hua L, Hao R, Ning H, Ru-Xian C and Li-Jie Y: Bioactive secondary metabolite study and strain identification of planomonospora sp. 12 from acanthopanax senticosus. Chin J Antibiotics 40: 321-324, 349, 2019.

9. Radhakrishnan SK, Bhat UG, Hughes DE, Wang IC, Costa RH and Gartel AL: Identification of a chemical inhibitor of the oncogenic transcription factor forkhead box M1. Cancer Res 66 : 9731-9735, 2006.

10. Nakano I, Joshi K, Visnyei K, Hu B, Watanabe M, Lam D, Wexler E, Saigusa K, Nakamura Y, Laks DR, et al: Siomycin A targets brain tumor stem cells partially through a MELK-mediated pathway. Neuro Oncol 13: 622-634, 2011.

11. Liu L, Liu AH and Ren H: Bioactive secondary metabolite study and strain identification of Planomonospora sp.12 from Acanthopanax senticosus. Chin J Antibiotics 40: 321-324, 349, 2015.

12. Qian AR, Li D, Han J, Gao X, Di SM, Zhang W and Shang P: Fractal dimension as a measure of altered actin cytoskeleton in MC3T3-E1 cells under simulated microgravity using 3-D/2-D clinostats. IEEE Trans Biomed Eng 59: 1374-1380, 2012.

13. Sethi S, Kumar R and Gupta S: Antibiotic production by microbes isolated from soil. Int J Pharmaceutical Sci Res 4: 2967, 2013.

14. Kuniko M, Mhionogi E and Hideo O: Studies on siomycin. III Structural features of siomycin A. J Antibiotics 22: 434-441, 1969.

15. Myatt SS and Lam EW: The emerging roles of forkhead box (Fox) proteins in cancer. Nat Rev Cancer 7: 847-859, 2007.

16. Okabe H, Satoh S, Kato T, Kitahara O, Yanagawa R, Yamaoka Y and Nakamura Y: Genome-wide analysis of gene expression in human hepatocellular carcinomas using cDNA microarray: Identification of genes involved in viral carcinogenesis and tumor progression. Cancer Res 61: 2129-2137, 2001.

17. Nakamura T, Furukawa Y, Nakagawa $H$, Tsunoda $T$, Ohigashi H, Murata K, Ishikawa O, Ohgaki K, Kashimura N, Miyamoto M, et al: Genome-wide cDNA microarray analysis of gene expression profiles in pancreatic cancers using populations of tumor cells and normal ductal epithelial cells selected for purity by laser microdissection. Oncogene 23: 2385-2400, 2004.
18. Bektas N, Ten Haaf A, Veeck J, Wild PJ, Lüscher-Firzlaff J, Hartmann A and Dahl E: Tight correlation between expression of the Forkhead transcription factor FOXM1 and HER2 in human breast cancer. BMC Cancer 8: 42, 2008.

19. Garber ME, Troyanskaya OG, Schluens K, Petersen S, Thaesler Z, Pacyna-Gengelbach M, van de Rijn M, Rosen GD, Perou CM, Whyte RI, et al: Diversity of gene expression in adenocarcinoma of the lung. Proc Natl Acad Sci USA 98: 13784-13789, 2001.

20. van den Boom J, Wolter M, Kuick R, Misek DE, Youkilis AS, Wechsler DS, Sommer C, Reifenberger G and Hanash SM: Characterization of gene expression profiles associated with glioma progression using oligonucleotide-based microarray analysis and real-time reverse transcription-polymerase chain reaction. Am J Pathol 163: 1033-1043, 2003.

21. Obama K, Ura K, Li M, Katagiri T, Tsunoda T, Nomura A, Satoh S, Nakamura Y and Furukawa Y: Genome-wide analysis of gene expression in human intrahepatic cholangiocarcinoma. Hepatology 41: 1339-1348, 2005.

22. Wan X, Choh Y, Kim SY, Dolan JG, Ngo VN, Burkett S, Khan J, Staudt LM and Helman LJ: Identification of the FoxM1/Bublb signaling pathway as a required component for growth and survival of rhabdomyosarcoma. Cancer Res 72: 5889-5899, 2012.

23. Jiang LZ, Liu YN, Wen TY and Chen HY: Down-regulation of forkhead box protein M1 by siomycin A can inhibit the malignant behaviors of laryngeal carcinoma cells. Academic J Second Military Med Univ 37: 963-968, 2016.

24. Elmore S: Apoptosis: A review of programmed cell death. Toxicol Pathol 35: 495-516, 2007.

25. Henry CM, Hollville E and Martin SJ: Measuring apoptosis by microscopy and flow cytometry. Methods 61: 90-97, 2013.

26. Jiang L, Wang P and Chen H: Overexpression of FOXM1 is associated with metastases of nasopharyngeal carcinoma. Ups J Med Sci 119: 324-332, 2014.

27. Xue YJ, Xiao RH, Long DZ, Zou XF, Wang XN, Zhang GX, Yuan YH, Wu GQ, Yang J, Wu YT, et al: Overexpression of FoxM1 is associated with tumor progression in patients with clear cell renal cell carcinoma. J Transl Med 10: 200, 2012.

28. Zhang Y, Zhang N, Dai B, Liu M, Sawaya R, Xie K and Huang S: FoxM1B transcriptionally regulates vascular endothelial growth factor expression and promotes the angiogenesis and growth of glioma cells. Cancer Res 68: 8733-8742, 2008.

29. Ahmed M, Uddin S, Hussain AR, Alyan A, Jehan Z, Al-Dayel F, Al-Sobhi S, Amin T, Bavi P and Al-Kuraya KS: FoxM1 and its association with matrix metalloproteinases (MMP) signaling pathway in papillary thyroid carcinoma. J Clin Endocrinol Metab 97: E1-E13, 2012.

30. Ghosh S, Kaplan KJ, Schrum LW and Bonkovsky HL: Cytoskeletal proteins: Shaping progression of hepatitis c virus-induced liver disease. Int Rev Cell Mol Biol 302: 279-319, 2013.

31. Malhotra SK and Shnitka TK: Chapter 1 the cytoskeletonmicrotubules and microfilaments: A biological perspective. Principles Med Biol 4: 1-41, 1996.

This work is licensed under a Creative Commons Attribution-NonCommercial-NoDerivatives 4.0 International (CC BY-NC-ND 4.0) License. 